\title{
Dynamic instability of genomic methylation patterns in pluripotent stem cells
}

\author{
Steen KT Ooi ${ }^{1,7}$, Daniel Wolf ${ }^{2}$, Odelya Hartung ${ }^{3}$, Suneet Agarwal ${ }^{3,4}$, George Q Daley ${ }^{3,4,5,6}$, Stephen P Goff ${ }^{2}$,
} Timothy H Bestor ${ }^{1 *}$

\begin{abstract}
Background: Genomic methylation patterns are established during gametogenesis, and perpetuated in somatic cells by faithful maintenance methylation. There have been previous indications that genomic methylation patterns may be less stable in embryonic stem (ES) cells than in differentiated somatic cells, but it is not known whether different mechanisms of de novo and maintenance methylation operate in pluripotent stem cells compared with differentiating somatic cells.

Results: In this paper, we show that ablation of the DNA methyltransferase regulator DNMT3L (DNA methyltransferase 3-like) in mouse ES cells renders them essentially incapable of de novo methylation of newly integrated retroviral DNA. We also show that ES cells lacking DNMT3L lose DNA methylation over time in culture, suggesting that DNA methylation in ES cells is the result of dynamic loss and gain of DNA methylation. We found that wild-type female ES cells lose DNA methylation at a much faster rate than do male ES cells; this defect could not be attributed to sex-specific differences in expression of DNMT3L or of any DNA methyltransferase. We also found that human ES and induced pluripotent stem cell lines showed marked but variable loss of methylation that could not be attributed to sex chromosome constitution or time in culture.

Conclusions: These data indicate that DNA methylation in pluripotent stem cells is much more dynamic and errorprone than is maintenance methylation in differentiated cells. DNA methylation requires DNMT3L in stem cells, but DNMT3L is not expressed in differentiating somatic cells. Error-prone maintenance methylation will introduce unpredictable phenotypic variation into clonal populations of pluripotent stem cells, and this variation is likely to be much more pronounced in cultured female cells. This epigenetic variability has obvious negative implications for the clinical applications of stem cells.
\end{abstract}

\section{Background}

De novo DNA methylation occurs primarily in nondividing germ cells in a sexually dimorphic manner [1]. A key regulator of de novo methylation is the DNA methylation cofactor/adaptor DNMT3L (DNA methyltransferase 3-like). Genetic studies show that DNMT3L is required for the establishment of genomic imprints in growing oocytes [2] and for de novo methylation at retrotransposons in prospermatogonia [3]. Although DNMT3L possesses the structural folds present in all catalytically active mammalian DNA methyltransferases [4], it lacks the functional domains required for catalytic

\footnotetext{
* Correspondence: thb12@columbia.edu

'Department of Genetics and Development, Columbia University, New York, USA

Full list of author information is available at the end of the article
}

activity, and is unable on its own to cause DNA methylation [5]. Biochemical studies have demonstrated that DNMT3L can function as a regulator of the DNA methyltransferases DNMT3A and DNMT3B [6]. DNMT3L is not expressed in differentiated somatic cells but is expressed in embryonic stem (ES) cells, which are known to be highly active in DNA methylation $[7,8]$. We previously showed that DNMT3L forms a complex with DNMT3A2 and DNMT3B, and that this complex specifically binds to nucleosomes that are unmethylated at lysine 4 of histone H3 (H3K4) [4]. Biochemical studies revealed that DNMT3L interacts via the $\mathrm{N}$-terminal cysteine-rich region with the $\mathrm{N}$ terminal tail of histone $\mathrm{H} 3$, and that this interaction is abolished by di- or trimethylation of H3K4. This resulted in the postulation of the DNMT3L histone recognition hypothesis, which
C Biomed Central

C 2010 Ooi et al; licensee BioMed Central Ltd. This is an Open Access article distributed under the terms of the Creative Commons Attribution License (http://creativecommons.org/licenses/by/2.0), which permits unrestricted use, distribution, and reproduction in any medium, provided the original work is properly cited. 
states that recognition of DNA methylation target sequences is dependent on the ability of DNMT3L to bind the histone $\mathrm{H} 3 \mathrm{~N}$-terminus and that regulation of H3K4 methylation plays a role in targeted de novo DNA methylation. It is interesting to note that genomewide analysis of DNA methylation and H3K4 methylation, particularly di- and tri-methylation, reveals a mutually exclusive distribution [9], supporting the notion that H3K4 methylation protects promoter regions from de novo methylation.

Maintenance methylation is very stable in differentiated/somatic cells, and DNA that is methylated in predetermined patterns maintains this methylation pattern for $>80$ cell divisions in transfected cells [10]. This stability is a consequence of recognition of hemimethylated DNA after DNA replication by DNMT1 and the regulatory factor UHRF1 (ubiquitin-like, containing PHD and RING finger domains 1) [11]. Both DNMT1 and UHRF1 bind to hemimethylated CpG dinucleotides, and deficiency in either factor results in genomewide demethylation and embryonic lethality [12-14]. Additional mechanisms are likely to be involved in the correct recruitment of both DNMT1 and UHRF1. The observation that UHRF1 is able to bind to histone H3 that is di- or trimethylated at lysine 9 [15] implies the involvement of other chromatin factors.

Mitotic inheritance of genomic methylation patterns has been reported to be less faithful in ES cells than in differentiated somatic cells. A study of imprinted loci by Dean et al. [16] and Humphreys et al. [17] reported that methylation imprints are gained and lost at high rates in clonal populations of ES cells, although the mechanism of this was not apparent. Zvetkova et al. [18] reported spontaneous loss of methylation at imprinted and repeat sequences specifically in female ES cells; this was attributed to lower levels of DNMT3A/DNMT3B in XX cells.

We report here that mouse ES cells that lack DNMT3L lose methylation during culture, unlike nonstem cells, which maintain methylation patterns in the absence of DNMT3L. Loss of DNA methylation is much more rapid in female than in male mutant ES cells, even though levels of DNA methyltransferases and DNMT3L are the same in male and female ES cells. We also found that human ES and induced pluripotent stem (iPS) cells tend to lose DNA methylation spontaneously in a process that is independent of sex and passage number. Whereas maintenance methylation in non-stem cells is mediated by the faithful copying of methylation patterns at $\mathrm{S}$ phase, stem cell-specific maintenance of genomic methylation patterns involves dynamic demethylation and de novo methylation, which leads to heterogeneous methylation within clonal cell populations. This instability has the potential to cause dysregulation of imprinted genes and other gene expression abnormalities. Epigenetic instability is likely to introduce unpredictable phenotypic variation into clonal populations of ES and iPS cells, and the effect will be more severe when the cells are female.

\section{Results}

Previous studies have demonstrated a requirement for DNMT3A and DNMT3B in the establishment of methylation in newly integrated Moloney murine leukemia virus (Mo-MLV) in ES cells [19]. We determined whether the regulatory factor DNMT3L was also required for this process. To allow the specific detection of the newly integrated retrovirus from the many copies endogenous to the mouse genome, we generated a Mo-MLV carrying an arbitrary $42 \mathrm{bp}$ insertion within the $\mathrm{U} 3$ region of the long terminal repeat (LTR), (Mo-MLV ${ }^{42 \mathrm{bp} / \mathrm{GFP}}$ ) (Figure 1a). The retroviral construct was further rendered resistant to TRIM28-ZFP809 mediated-restriction $[19,20]$ by replacement of the transfer ( $\mathrm{t}$ )RNA ${ }^{\text {Pro }}$ primer binding site (PBS) with a tRNA ${ }^{\text {Gln }}$ PBS. This made the provirus largely resistant to TRIM28-ZFP809-dependent transcriptional silencing (Figure 1b). However, infection of wild-type ES cells resulted in the gradual silencing of proviral expression during passage. Ablation of DNMT3L largely prevented the passage-dependent silencing of retroviral transcription that occurs in the presence of DNMT3L, and this lack of silencing activity was associated with a failure to methylate the LTRs of the Mo-MLV ${ }^{42 \mathrm{bp} / \mathrm{GFP}}$ retrovirus (Figure 1c).

It was surprising to find that female (XX) ES cells were much less proficient at provirus methylation than were male (XY) ES cells (Figure 1d), both in the presence and absence of DNMT3L. Also surprising was the DNMT3L-independent de novo methylation of the Oct4 promoter (Figure 1e), which normally occurs when ES cells are induced to differentiate [20]. However, there are both DNMT3L-dependent and -independent de novo methylation events in germ cells $[2,3]$.

As shown in Figure 2a, DNMT3L is required for the maintenance of genomic methylation patterns in ES cells. DNMT3L is not required for maintenance methylation in somatic cells, as it is not expressed in differentiated somatic cells, and ablation of DNMT3L results in normal DNA methylation and normal mouse development [1]. Both Dnmt3L $L^{-/-}$and Dnmt3 $3^{+/+}$XX ES cells lost methylation at much higher rates than did XY ES cells (Figure 2b). All eight independent XX ES cell lines tested showed much greater loss of methylation than did the three XY cell lines tested (Figure 2c).

It had been previously reported that wild-type XX ES cells lose methylation with continued passage in culture, with reduced expression of both DNMT3A and DNMT3B in XX cells being reported as the cause [18]. However, our quantitative immunoblot analysis $\left(\right.$ Odyssey $^{\oplus}$ Infrared 


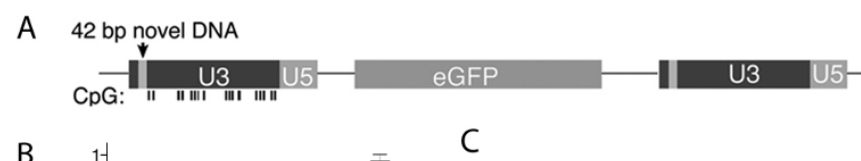

B
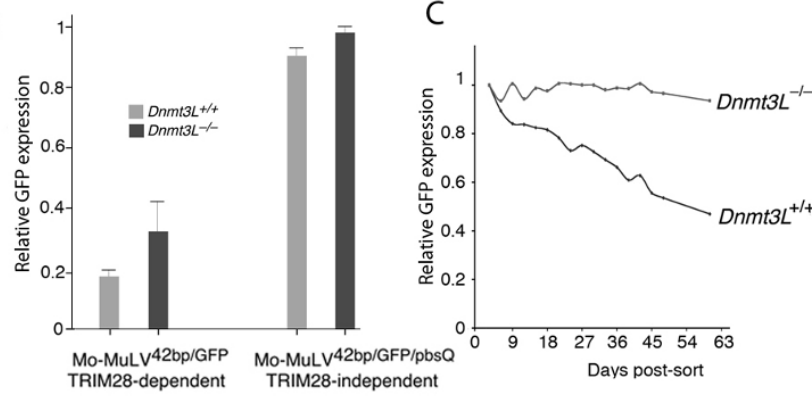

D Dnmt3L $^{+1+}$

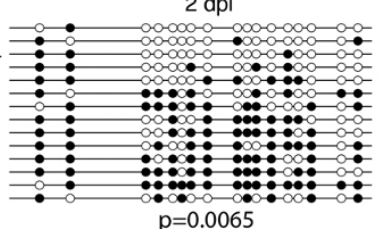

Dnmt3L
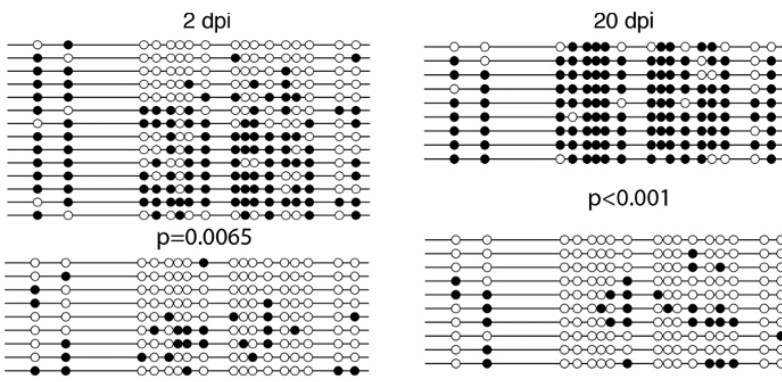

$\mathrm{p}<0.001$

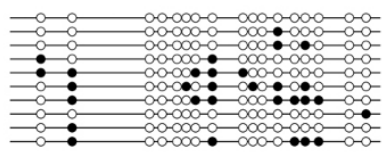

$\mathrm{E}$

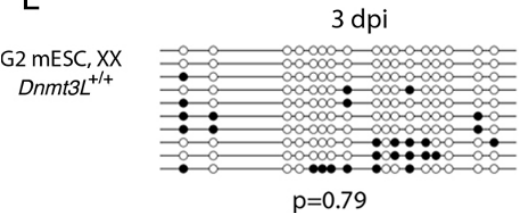

B5 $\mathrm{mESC}, \mathrm{XX}$ Dnmt3L ${ }^{--}$

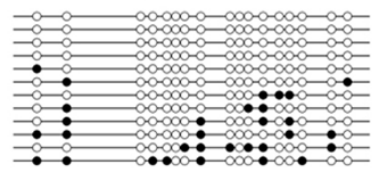

$3 \mathrm{dpi}$

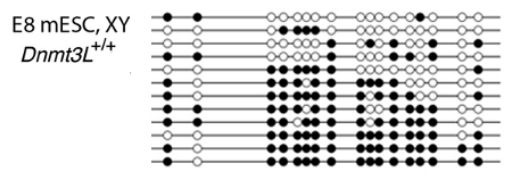

$p=0.0266$

A5 $\mathrm{mESC}, \mathrm{XY}$
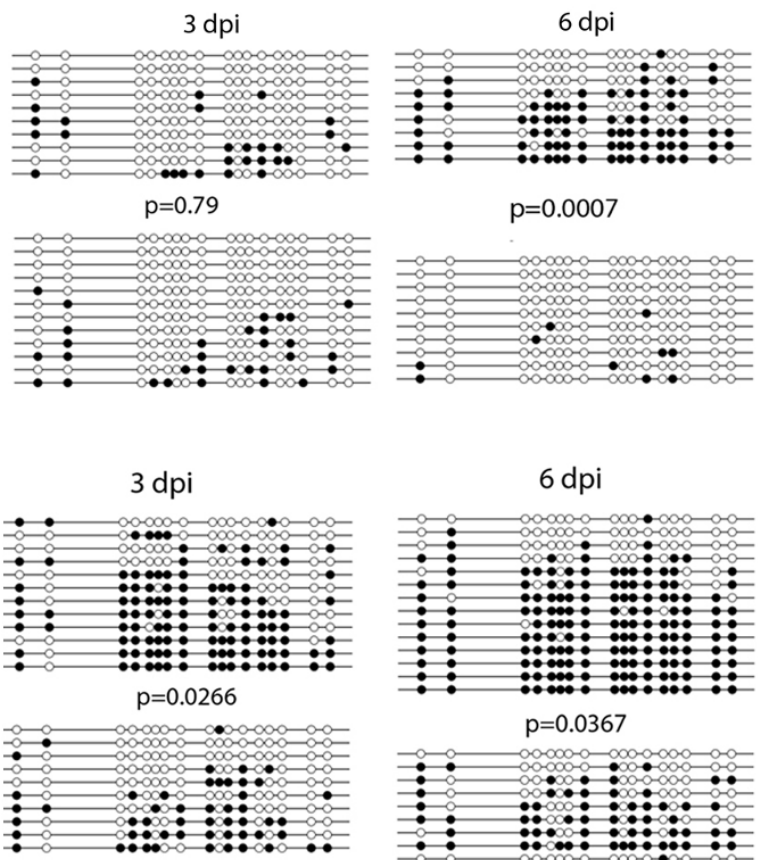

$6 \mathrm{dpi}$

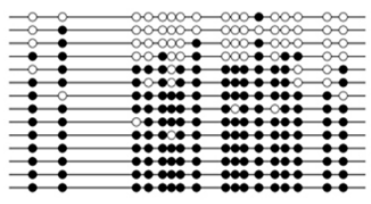

$p=0.0367$

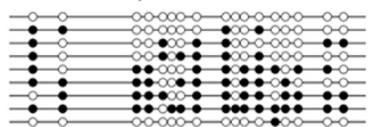

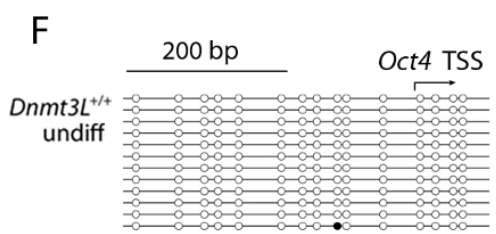

vs. undiff: $p<0.001$

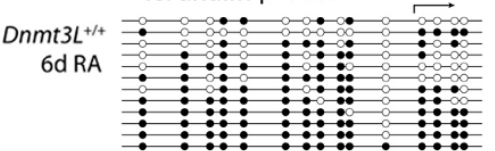

vs. undiff: $p=0.14$

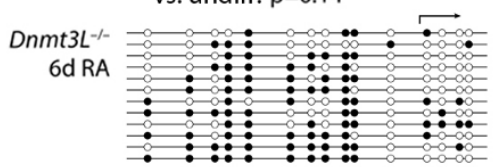

Figure 1 De novo methylation of proviral DNA requires DNMT3L (DNA methyltransferase 3-like). (a) Retrovirus reporter construct with long terminal repeats (LTRs) modified to allow identification of reporter provirus against background of endogenous retroviruses. (b) Replacement of primer binding site relieved TRIM28-ZFP809 mediated silencing, and the primer binding site was changed to be complementary to glutamine (Q) transfer (t)RNA. (c) Embryonic stem (ES) cells lacking DNMT3L were unable to silence the retrovirus shown in (a). Green fluorescent protein (GFP)-expressing cells were isolated by flow sorting 3 days post-infection (dpi), and GFP expression was monitored by fluorescence-activated cell sorting over the time period indicated. (d) Lack of retrovirus silencing accompanied lack of LTR methylation. (e) Wild-type female ES cells were inefficient in de novo methylation, and methylation defect in female ES cells was seen in wild-type cells but was more severe in Dnmt3L ${ }^{-1}$ ES cells. (f) De novo methylation of Oct4 $5^{\prime}$ region was not affected by loss of DNMT3L. All $P$ values were obtained by the non-parametric two-tailed Mann-Whitney test. 


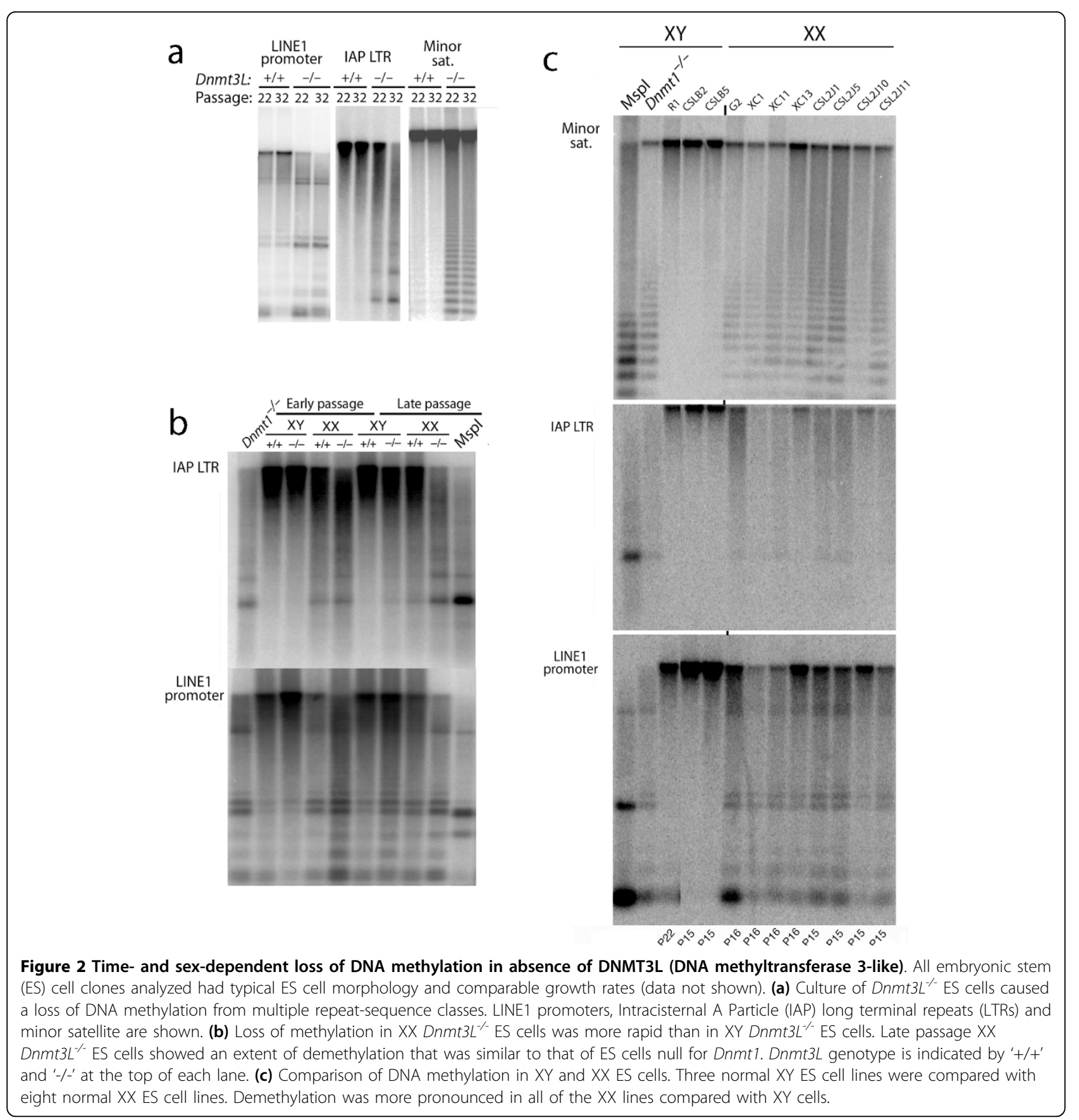

Imaging System; Li-COR Biotechnology, Lincoln, NB, USA) showed that levels of DNMT1, DNMT3A, DNMT3B and DNMT3L were very similar in XX and XY ES cells (Figure $3 \mathrm{a}-\mathrm{c}$ ), and that their levels were very similar in early and late passage ES cells (Figure 3a, b). The numerous isoforms of DNMT3B that arise via alternative splicing were also very similar in XX and XY ES cells (Figure 3a, b). These data indicate that the cause of XX-specific demethylation is not reduced expression of DNA methyltransferases.
The finding that DNMT3L is required for de novo methylation of retroviral DNA allowed us to test the importance of the interaction of DNMT3L with unmethylated H3K4. Mutations that caused amino acid substitutions at positions necessary for the interaction of DNMT3L and histone H3 [4] were introduced into DNMT3L expression constructs and stably expressed in ES cells. The recombinant proteins were stable and were expressed at levels equal to or greater than that of endogenous DNMT3L or of transfected wild-type DNMT3L 


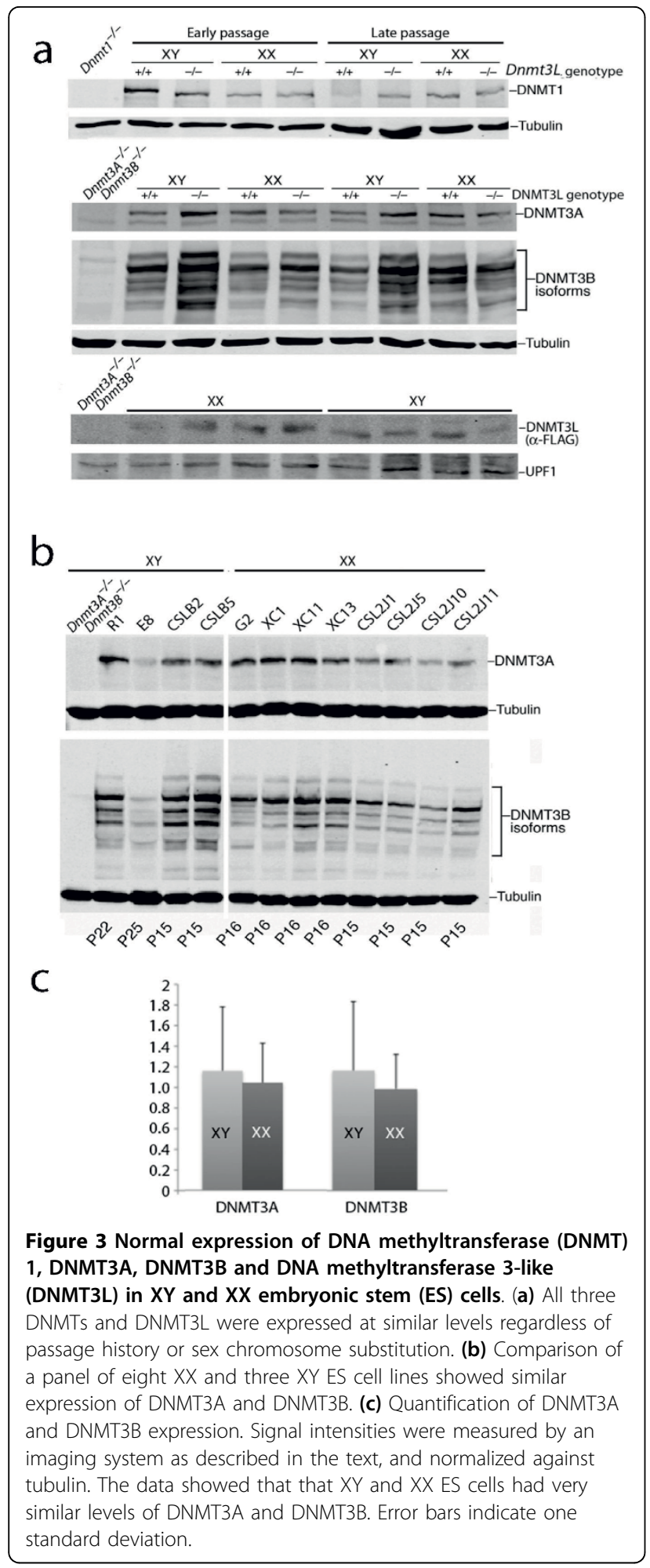

(Figure 4a). Disruption of the DNMT3L-H3K4 interaction caused a partial reduction of methylation in the case of the D124A substitution and a severe reduction in de novo methylation in the case of the I141W mutation (Figure 4b). These data indicate that the bulk of $d e$ novo methylation mediated by DNMT3L is probably regulated by the association of unmethylated DNA with nucleosomes that are enriched in unmethylated H3K4.

The finding that mouse ES cells display sex-specific epigenetic instability suggested that human ES and iPS cells might show a similar instability. Human ES and iPS lines were tested for loss of methylation at LINE1 transposon promoters, $\alpha$-satellite DNA, satellite 2 DNA from chromosomes 1 and 16, and satellite 3 DNA from chromosome 9. All human ES and iPS lines showed loss of methylation at $\alpha$-satellite DNA, and two human ES lines and two iPS lines showed marked demethylation of satellite 3 and LINE1 promoters; satellite 2 was not affected in any cell line (Figure 5). Demethylation was not strongly associated with passage history or sex chromosome constitution, and the N1 and D10 iPS lines showed greater demethylation at early than at later passages. These data indicate that human ES and iPS cells are subject to marked epigenetic instability under conditions of normal ex vivo propagation.

\section{Discussion}

ES and embryonic carcinoma cells are known for their ability to potently restrict retroviral expression $[7,8]$, which involves two phases. The initial phase, which immediately follows retroviral integration, depends on the interaction of retroviral DNA sequences with host restriction factors, which include TRIM28 [21] and ZFP809 [22]. Maintenance of this repression is subsequently thought to rely on epigenetic mechanisms, primarily DNA methylation. Clonal studies in ES cells using murine stem cell virus (MSCV) transduction followed by knockdown of DNMT3A and/or DNMT3B showed that maintenance of DNA methylation is important for stable proviral silencing [23], and 5-azacytidineinduced demethylation of previously methylated and silent MSCV provirus resulted in their reactivation [24]. Both these observations suggest that DNA methylation is necessary to enforce provirus silencing. By starting with a population of ES cells in which integrated provirus has escaped the initial silencing system by virtue of replacement of the primer binding site to prevent binding of ZFP809, we investigated the role of DNMT3L-mediated DNA methylation acquisition in the gradual silencing of active retrovirus. We found that the ability to silence over time is dependent on the ability to acquire methylation at proviral LTRs.

Whereas DNMT3L was found to be necessary for de novo methylation of newly integrated proviral DNA, it was dispensable for de novo methylation at a promoter after induction of differentiation. In vitro differentiation of ES cells is known to coincide with de novo methylation at over $300 \mathrm{CpG}$-poor regions that are in proximity to gene promoters [25]. This is evidence of DNMT3L- 


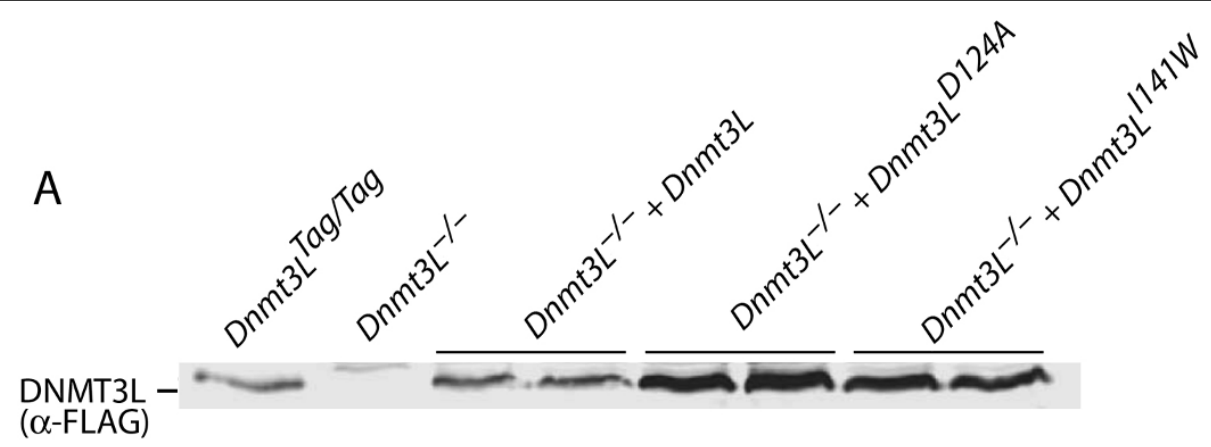

B
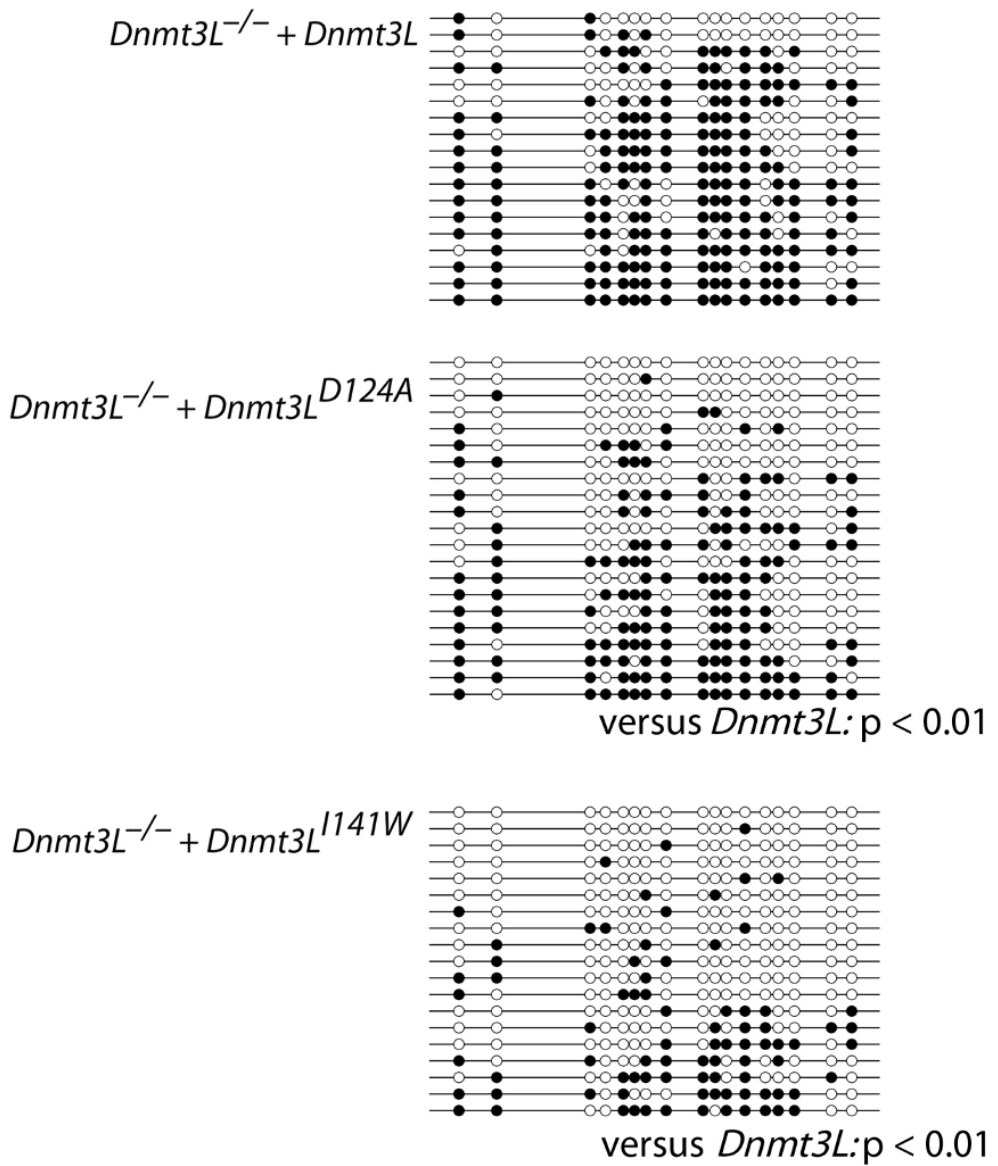

Figure 4 DNMT3L (DNA methyltransferase 3-like) that is unable to bind unmethylated H3K4 is deficient in rescue of the de novo methylation defect in Dnmt3L ${ }^{-/}$embryonic stem (ES) cells. The D90A and I107W substitutions were previously shown to prevent binding of human DNMT3L to histone H3 peptide unmethylated at lysine position 4 (H3K4) [4]. The equivalent residues in mouse DNMT3L are D124A and I141W, respectively. (a) The mutant proteins were stable and were expressed at higher levels than the wild-type protein; two independent stable transfectants are shown for each. (b) Failure of mutant DNMT3L to rescue the de novo methylation defect. The long terminal repeat (LTR) of the retrovirus shown in Figure 1 (a) was tested for de novo methylation at 12 days post-infection. These data demonstrate that de novo methylation in ES cells requires the interaction of DNMT3L and unmethylated H3K4.

independent de novo methylation, which had been previously reported [2,3]. It is not clear whether the low density of DNA methylation actually represses transcription or whether the de novo methylation of the CpGpoor Oct4 promoter is actually involved in Oct4 regulation.
Previous studies in mouse ES and iPS cells have reported that the presence of two $\mathrm{X}$ chromosomes causes genomewide hypomethylation $[18,26]$. Our quantitative studies examined the expression levels of DNMT1, DNMT3A and DNMT3B in XX and XY ES cells, and revealed that the increased rate of loss of 


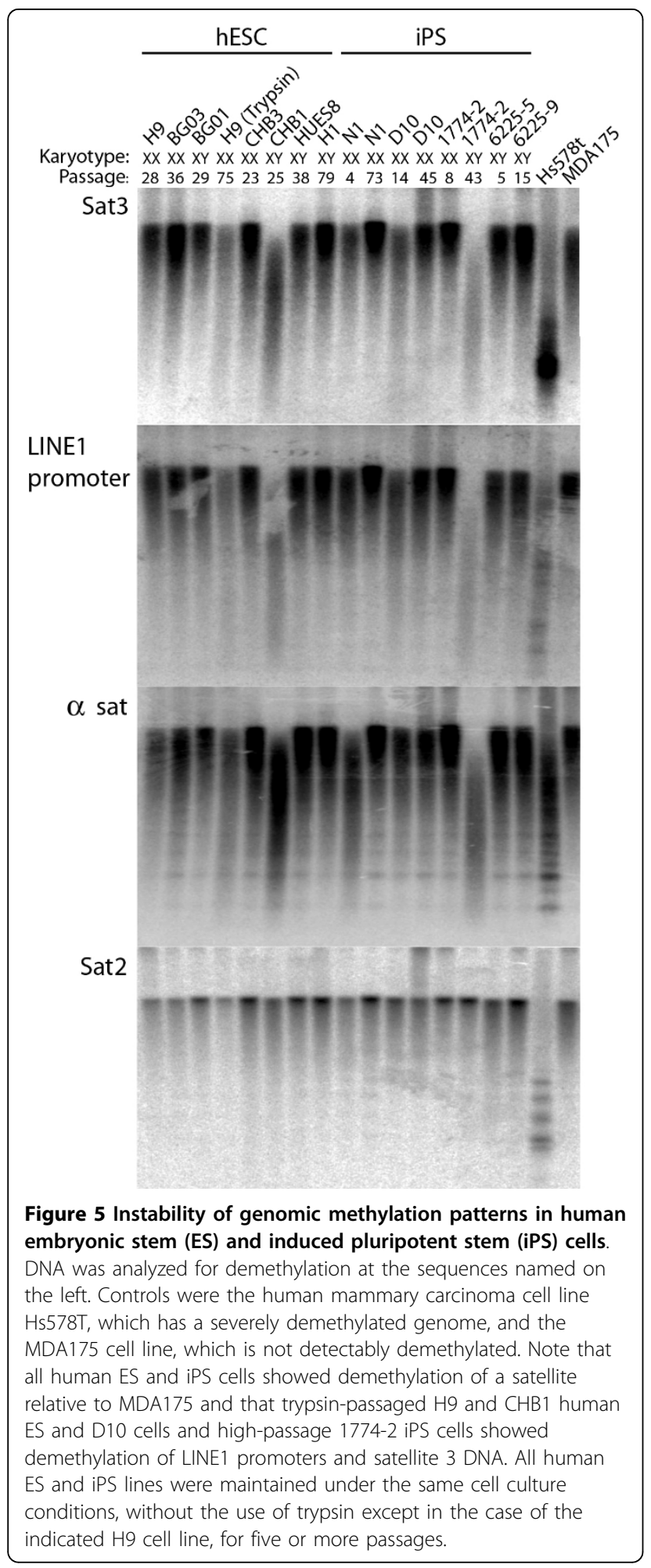

DNA methylation in XX versus XY ES cells cannot be attributed to reduced amounts of DNA methyltransferase proteins. It is instead consistent with some inherent difference between XX and XY ES cells, which affects DNMT recruitment and general regulation of DNA methylation. XX cells may have a higher rate of loss of methylation or a lower rate of remethylation, or both. The observation that DNMT3L deficiency results in hypomethylation at retrotransposons and minor satellite sequences is also in contrast to previously published results, which claimed that DNMT3L was dispensable for their methylation [27]. Given that we observed a passage-dependent effect on the ability to maintain methylation in the absence of DNMT3L (Figure 2a, b), we propose that this discrepancy might be attributable to lower passage numbers of the DNMT3L-deficient ES cells used in the earlier analysis.

Two previous studies reported that the active methyltransferases DNMT3A and DNMT3B were required for methylation content to be maintained at normal levels $[28,29]$. Our study is the first to demonstrate that the catalytically inactive adaptor DNMT3L is required for normal DNA methylation in pluripotent stem cells. DNMT3L is not expressed in differentiated somatic cells, yet unlike Dnmt3L-deficient ES cells, they are able to maintain genomic methylation patterns with high fidelity. These findings indicate that methylation patterns in ES cells are the product of the dynamic gain and loss of DNA methylation, rather than passive clonal inheritance as occurs in differentiated cells. This places a higher load on non-maintenance methylation-based mechanisms, which involve DNMT3 family members. We speculate that there are at least two possible explanations why maintenance methylation-based mechanisms (that is, those involving DNMT1 and UHRF1) are less effective in ES cells. First, ES cells contain combinations of histone modifications not observed in differentiated somatic cells, which could adversely affect recruitment of DNMTs and other factors involved in maintenance methylation. Among these is bivalent methylation of H3K4 and H3K27, two methylation markers that are usually mutually exclusive [30]. Although it has been shown that UHRF1 binds to di- and trimethylated H3K9 [15], the consequences of H3K27 methylation and of other ES cell-specific patterns of chromatin modifications are unknown but are likely to be responsible for some of the epigenetic instability that occurs in pluripotent stem cells. Second, 5-hydroxymethyl cytosine $\left(\mathrm{hm}^{5} \mathrm{C}\right)$ is present in DNA of ES cells, [31] and structural models indicate that UHRF1 cannot bind to $\mathrm{hm}^{5} \mathrm{C}$ [32]. If $\mathrm{hm}^{5} \mathrm{C}$ occurs within CpG dinucleotides, this could lead to inefficient maintenance methylation. However, the sequence contexts in which $\mathrm{hm}^{5} \mathrm{C}$ occurs in vivo are not known, and the role of this modified base in maintenance methylation is unclear.

\section{Conclusions}

The most significant feature of unstable genomic methylation patterns in pluripotent stem cells may be the 
introduction of stochastic phenotypic variation into clonal cell populations, particularly with regard to genome destabilization, selection of cells that have increased expression of genes that stimulate cell growth, and the unpredictable gain and loss of imprinted gene expression. It should be noted that cultured ES cells are derived from cell types that exist only transiently in vivo. Selective pressures for high genetic [33] or epigenetic stability are therefore low in vivo. The forced ex vivo propagation of ES cells for a far greater number of cell divisions than are undergone by their in vivo counterparts renders cultured stem cells - both ES and iPS cells -vulnerable to increased genetic and epigenetic instability.

\section{Methods}

\section{Cell culture and sample preparation}

DNMT3L-deficient ES cells were derived from crosses between $D n m t 3 L^{+/-}$animals [2] using a previously described protocol [34]. Dnmt1 $1^{-/-}$and $D n m t 3 a^{-/}$; Dnmt $3 b^{-1-}$ ES cells (generously provided by E. Li, Novartis, MA, USA) have also been described previously [19]. Mouse ES cells were cultured on gelatinized tissue culture plates in ES cell media (Dulbecco modified Eagle medium (DMEM) supplemented with 15\% fetal bovine serum, $100 \mathrm{IU} / \mathrm{mL}$ penicillin, $100 \mathrm{mg} / \mathrm{mL}$ streptomycin, $2 \mathrm{mmol} / \mathrm{L} \mathrm{L}$-glutamine, MEM non-essential amino acids, $0.12 \mathrm{mmol} / \mathrm{L} \beta$-mercaptoethanol, and leukemia inhibitory factor (LIF) from the conditioned medium of LIF-secreting cells. Human ES and iPS cells were cultured on $\gamma$-irradiated (CF1-derived) mouse embryonic fibroblasts (GlobalStem Inc., Rockville, MD, USA) in standard human ES media (DMEM/F-12; Stem Cell Technologies Inc., Vancouver, BC, Canada) supplemented with $20 \%$ knockout serum, $1 \mathrm{mM}$ L-glutamine and $100 \mu \mathrm{M}$ MEM-nonessential amino acids (Invitrogen Corp., Carlsbad, CA, USA), $100 \mu \mathrm{M}$ 2-mercaptoethanol (Sigma Chemical Co., St Louis, MO, USA) and 10ng/ml recombinant human bFGF (Invitrogen). Both mouse and human ES and iPS cell DNA was purified using a commercial kit (DNeasy ${ }^{\odot}$ Blood and Tissue Kit; Qiagen Inc., Valencia, CA, USA).

\section{Flow cytometry}

For sorting experiments, green fluorescent protein-positive ES cells were purified on a cell sorter (FACSAria Cell Sorter; BD Biosciences, San Jose, CA, USA), and analyses performed on an automated cell analyzer (FACSCalibur Cell Analyzer; BD Biosciencs).

\section{Methylation analysis}

Retroviral preparation and transduction was performed as described previously [19]. For analysis of Mo$\mathrm{MLV}^{40 \mathrm{bp} / \mathrm{GFP}}$, bisulfite conversion using the method described by Hajkova and colleagues [35] was used. For Oct4 promoter analysis, DNA was converted using a commercial kit (EZ DNA Methylation Gold ${ }^{\mathrm{TM}} \mathrm{Kit}$; Zymo Research Corp., Orange, CA, USA). Analysis and statistical comparison of bisulfite data was performed using QUMA software http://quma.cdb.riken.jp/[36]. For methylation-sensitive Southern blots, DNA was subjected to 2 rounds of digestion with either methylation-sensitive HpaII or the methylation-insensitive isoschizomer MspI (New England Biolabs Inc., Ipswich, MA, USA) to ensure complete digestion. Briefly, DNA was purified from cell pellets (fresh or frozen) using a commercial kit (DNeasy Kit; Qiagen) according to the manufacturer's protocol and quantified, before digesting using a 10-fold unit excess of enzyme. After digestion, DNA was precipitated with ethanol and digested a second time. Digestions were performed for between 4 and 6 hours. Digested DNA was resolved in 1\% agarose gels, before being transferred onto a nylon membrane. After ultraviolet-induced cross-linking, membranes were incubated at $65^{\circ} \mathrm{C}$ with prehybridization solution $(6 \times$ saline sodium citrate buffer, $10 \times$ Denhardt solution, $1 \%$ sodium dodecyl sulfate, $10 \%$ dextran sulfate). LINE1 and Intracisternal A Particle (IAP) probes were used as described previously [37]. The minor satellite probe used has also been described previously [38]. Probes were incubated with membranes overnight, before washing and exposure to phosphor screens (Phosphorimager; Molecular Dynamics, Sunnyvale, CA, USA).

\section{Statistical analysis}

All statistical comparisons were carried out using the non-parametric two-tailed Mann-Whitney test.

\section{Antibodies}

For western blotting, the antibodies used were: anti-DNMT1 rabbit polyclonal (pATH52) [37] 1: 800; anti-DNMT3A (SC-20703; Santa Cruz Biotechnologies, Santa Cruz, CA, USA) 1:100; anti-DNMT3B (SC-52922; Santa Cruz Biotechnologies) 1: 200; anti-tubulin mouse monoclonal (T6199; Sigma Chemical Co. St. Louis, MO, USA,); anti-UPF1 Rent1 (H300) (SC-48802; Santa Cruz Biotechnologies), anti-FLAG M2, mouse monoclonal (F3165; Sigma Chemical Co.) 1: 400. Horse radishconjugated secondary antibodies were obtained from Sigma Chemical Co. IR-800 antibodies used for the Li-Cor detection system were obtained from Rockland Immunochemicals (Gilbertsville, PA, USA).

\section{Primer sequences}

Primers used for bisulfite analysis were designed using MethPrimer [39]. The primer sets used are set out in Table 1 
Table 1 Primer sets used in the experiments

\begin{tabular}{|c|c|}
\hline Name & Sequence $5^{\prime} \rightarrow 3^{\prime}$ \\
\hline \multicolumn{2}{|c|}{ Nested primers for bisulfite analysis of Mo-MLVGFP long terminal repeat } \\
\hline$\overline{\text { GFPF1 }}$ & TПTTITATATATTATTATTTATTTTITा \\
\hline GFPR1 & ATCAATCACTCAAAAAAAACCCTC \\
\hline GFPF2 & TAGGGTTAAGAATAGATGGAATAGTTGA \\
\hline \multicolumn{2}{|c|}{ Bisulfite analysis of Oct4 promoter } \\
\hline Oct4F1 & TGAGGAGTGGTITAAGAAATAATTG \\
\hline Oct4R1 & AAACCAAATATCCAACCATAAAAAA \\
\hline Oct4R2 & CCAACCATAAAAAAAATAAACACC \\
\hline \multicolumn{2}{|c|}{ Mo-MLV $^{42 \mathrm{bp} / \mathrm{GFP}}$ creation $^{1}$} \\
\hline Forward & TTATACTCCTCCACACACCATCACTCACTCTITCTCAATCCA \\
\hline Reverse & TGGATTGAGAAAGAGTGAGTGATGGTGTGTGGAGGAGTATAA \\
\hline
\end{tabular}

\section{Acknowledgements}

This article is dedicated to the memory of our friend and colleague Dan Wolf (July 15, 1977-September 24, 2009). We thank E Li for the gift of 7aabb mutant ES cells, CS Lin and Z Wu for XX and XY ES cells, SP Lin for derivation of Dnmt3L $L^{-1-} E S$ cells and Z. A. Hilbert for assistance. Supported by grants from the $\mathrm{NIH}$ (to $S \mathrm{G}, \mathrm{G} Q \mathrm{D}$ and T H B). S. P G was supported by a grant from the State of New York Dept. of Health NYSTEM program. D W was an associate and S P G and G Q D are Investigators of the Howard Hughes Medical Institute.

\section{Author details}

'Department of Genetics and Development, Columbia University, New York, USA. ${ }^{2} \mathrm{HHMl}$ and Department of Biochemistry and Molecular Biophysics, College of Physicians and Surgeons of Columbia University, New York, USA. ${ }^{3}$ Stem Cell Program, Children's Hospital Boston, Boston, MA 02115, USA. ${ }^{4}$ Stem Cell Transplantation Program, Division of Pediatric Hematology/ Oncology, Manton Center for Orphan Disease Research, Howard Hughes Medical Institute, Children's Hospital Boston and Dana Farber Cancer Institute; Harvard Stem Cell Institute, Boston, MA 02115, USA. ${ }^{5}$ Division of Hematology, Brigham and Women's Hospital, Boston, MA 02115, USA. ${ }^{6}$ Department of Biological Chemistry and Molecular Pharmacology, Harvard Medical School, Boston, MA 02115, USA. 'UCL Cancer Institute, Paul O'Gorman Building, University College London, London, WC1E 6BT, UK.

\section{Authors' contributions}

SKTO, THB and DW contributed to the study design. SKTO, DW, OH and SA contributed to the experimental work. SKTO, THB, GD and SPG contributed to manuscript preparation. With the exception of DW, all authors read and approved the final manuscript.

\section{Competing interests}

The authors declare that they have no competing interests.

Received: 15 June 2010 Accepted: 24 September 2010 Published: 24 September 2010

\section{References}

1. Schaefer $C B$, Ooi SK, Bestor TH, Bourc'his D: Epigenetic decisions in mammalian germ cells. Science 2007, 316:398-399.

2. Bourc'his D, Xu GL, Lin CS, Bollman B, Bestor TH: Dnmt3L and the establishment of maternal genomic imprints. Science 2001, 294:2536-2539.

3. Bourc'his D, Bestor TH: Meiotic catastrophe and retrotransposon reactivation in male germ cells lacking Dnmt3L. Nature 2004, 431:96-99.
4. Ooi SK, Qiu C, Bernstein E, Li K, Jia D, Yang Z, Erdjument-Bromage H, Tempst $P$, Lin SP, Allis CD, et al: DNMT3L connects unmethylated lysine 4 of histone H3 to de novo methylation of DNA. Nature 2007, 448:714-717.

5. Chedin F, Lieber MR, Hsieh CL: The DNA methyltransferase-like protein DNMT3L stimulates de novo methylation by Dnmt3a. Proc Natl Acad Sci USA 2002, 99:16916-16921.

6. Suetake I, Shinozaki F, Miyagawa J, Takeshima H, Tajima S: DNMT3L stimulates the DNA methylation activity of Dnmt3a and Dnmt3b through a direct interaction. J Biol Chem 2004, 279:27816-27823.

7. Stewart CL, Stuhlmann H, Jahner D, Jaenisch R: De novo methylation, expression, and infectivity of retroviral genomes introduced into embryonal carcinoma cells. Proc Natl Acad Sci USA 1982, 79:4098-4102.

8. Lei H, Oh SP, Okano M, Juttermann R, Goss KA, Jaenisch R, Li E: De novo DNA cytosine methyltransferase activities in mouse embryonic stem cells. Development 1996, 122:3195-3205.

9. Edwards JR, O'Donnell AH, Rollins RA, Peckham HE, Lee C, Milekic MH, Chanrion B, Fu Y, Su T, Hibshoosh H, et al: Chromatin and sequence features that define the fine and gross structure of genomic methylation patterns. Genome Res 2010, 20:972-980.

10. Lorincz MC, Schubeler D, Goeke SC, Walters M, Groudine M, Martin DI: Dynamic analysis of proviral induction and De Novo methylation: implications for a histone deacetylase-independent, methylation density-dependent mechanism of transcriptional repression. Mol Cell Biol 2000, 20:842-850.

11. Ooi SK, Bestor TH: Cytosine methylation: remaining faithful. Curr Biol 2008, 18:R174-176

12. Li E, Bestor TH, Jaenisch R: Targeted mutation of the DNA methyltransferase gene results in embryonic lethality. Cell 1992 69:915-926.

13. Bostick M, Kim JK, Esteve PO, Clark A, Pradhan S, Jacobsen SE: UHRF1 plays a role in maintaining DNA methylation in mammalian cells. Science 2007, 317:1760-1764.

14. Sharif J, Muto M, Takebayashi SI, Suetake I, Iwamatsu A, Endo TA, Shinga J, Mizutani-Koseki Y, Toyoda T, Okamura K, et al: The SRA protein Np95 mediates epigenetic inheritance by recruiting Dnmt1 to methylated DNA. Nature 2007, 450(7171):908-12.

15. Rottach A, Frauer C, Pichler G, Bonapace IM, Spada F, Leonhardt H: The multi-domain protein Np95 connects DNA methylation and histone modification. Nucleic Acids Res 38:1796-1804.

16. Dean W, Bowden L, Aitchison A, Klose J, Moore T, Meneses JJ, Reik W, Feil R: Altered imprinted gene methylation and expression in completely ES cell-derived mouse fetuses: association with aberrant phenotypes. Development 1998, 125:2273-2282.

17. Humpherys D, Eggan K, Akutsu H, Hochedlinger K, Rideout WM, Biniszkiewicz D, Yanagimachi R, Jaenisch R: Epigenetic instability in ES cells and cloned mice. Science 2001, 293:95-97.

18. Zvetkova I, Apedaile A, Ramsahoye B, Mermoud JE, Crompton LA, John R, Feil R, Brockdorff N: Global hypomethylation of the genome in XX embryonic stem cells. Nat Genet 2005, 37:1274-1279.

19. Okano M, Bell DW, Haber DA, Li E: DNA methyltransferases Dnmt3a and Dnmt3b are essential for de novo methylation and mammalian development. Cell 1999, 99:247-257.

20. Hattori N, Nishino K, Ko YG, Ohgane J, Tanaka S, Shiota K: Epigenetic control of mouse Oct-4 gene expression in embryonic stem cells and trophoblast stem cells. J Biol Chem 2004, 279:17063-17069.

21. Wolf D, Goff SP: TRIM28 mediates primer binding site-targeted silencing of murine leukemia virus in embryonic cells. Cell 2007, 131:46-57.

22. Wolf D, Goff SP: Embryonic stem cells use ZFP809 to silence retroviral DNAs. Nature 2009, 458:1201-1204.

23. Minoguchi $\mathrm{S}$, Iba $\mathrm{H}$ : Instability of retroviral DNA methylation in embryonic stem cells. Stem Cells 2008, 26:1166-1173.

24. Yao S, Sukonnik T, Kean T, Bharadwaj RR, Pasceri P, Ellis J: Retrovirus silencing, variegation, extinction, and memory are controlled by a dynamic interplay of multiple epigenetic modifications. Mol Ther 2004, 10:27-36.

25. Mohn F, Weber M, Rebhan M, Roloff TC, Richter J, Stadler MB, Bibel M, Schubeler D: Lineage-specific polycomb targets and de novo DNA methylation define restriction and potential of neuronal progenitors. Mol Cell 2008, 30:755-766.

26. Maherali N, Sridharan R, Xie W, Utikal J, Eminli S, Arnold K, Stadtfeld M, Yachechko $R$, Tchieu J, Jaenisch $R$, et al: Directly reprogrammed fibroblasts 
show global epigenetic remodeling and widespread tissue contribution. Cell Stem Cell 2007, 1:55-70.

27. Hata K, Okano M, Lei H, Li E: Dnmt3L cooperates with the Dnmt3 family of de novo DNA methyltransferases to establish maternal imprints in mice. Development 2002, 129:1983-1993.

28. Liang G, Chan MF, Tomigahara Y, Tsai YC, Gonzales FA, Li E, Laird PW, Jones PA: Cooperativity between DNA methyltransferases in the maintenance methylation of repetitive elements. Mol Cell Biol 2002, 22:480-491.

29. Chen T, Ueda Y, Dodge JE, Wang Z, Li E: Establishment and maintenance of genomic methylation patterns in mouse embryonic stem cells by Dnmt3a and Dnmt3b. Mol Cell Biol 2003, 23:5594-5605.

30. Bernstein BE, Mikkelsen TS, Xie X, Kamal M, Huebert DJ, Cuff J, Fry B, Meissner A, Wernig M, Plath $\mathrm{K}$, et al: A bivalent chromatin structure marks key developmental genes in embryonic stem cells. Cell 2006, 125:315-326.

31. Tahiliani M, Koh KP, Shen Y, Pastor WA, Bandukwala H, Brudno Y, Agarwal S, lyer LM, Liu DR, Aravind L, Rao A: Conversion of 5-methylcytosine to 5hydroxymethylcytosine in mammalian DNA by MLL partner TET1. Science 2009, 324:930-935.

32. Hashimoto H, Horton JR, Zhang X, Bostick M, Jacobsen SE, Cheng X: The SRA domain of UHRF1 flips 5-methylcytosine out of the DNA helix. Nature 2008, 455:826-829.

33. Damelin M, Bestor TH: Decatenation checkpoint deficiency destabilizes the stem cell genome. Cell Cycle 2006, 5:345-346.

34. Nagy A, Gertsenstein M, Vintersten K, Behringer R: From Protocol 5: De Novo Isolation of ES Cell Lines from Blastocysts. Manipulating the Mouse Embryo: A Laboratory Manual Cold Spring Harbor Press 2003.

35. Hajkova P, el-Maarri O, Engemann S, Oswald J, Olek A, Walter J: DNAmethylation analysis by the bisulfite-assisted genomic sequencing method. Methods Mol Biol 2002, 200:143-154.

36. Kumaki Y, Oda M, Okano M: QUMA: quantification tool for methylation analysis. Nucleic Acids Res 2008, 36:W170-175.

37. Damelin $\mathrm{M}$, Bestor $\mathrm{TH}$ : Biological functions of DNA methyltransferase 1 require its methyltransferase activity. Mol Cell Biol 2007, 27:3891-3899.

38. Lehnertz B, Ueda Y, Derijck AA, Braunschweig U, Perez-Burgos L, Kubicek S, Chen T, Li E, Jenuwein T, Peters AH: Suv39h-mediated histone H3 lysine 9 methylation directs DNA methylation to major satellite repeats at pericentric heterochromatin. Curr Biol 2003, 13:1192-1200.

39. Li LC, Dahiya R: MethPrimer: designing primers for methylation PCRs. Bioinformatics 2002, 18:1427-1431.

doi:10.1186/1756-8935-3-17

Cite this article as: Ooi et al:: Dynamic instability of genomic methylation patterns in pluripotent stem cells. Epigenetics \& Chromatin 2010 3:17.

\section{Submit your next manuscript to BioMed Central and take full advantage of:}

- Convenient online submission

- Thorough peer review

- No space constraints or color figure charges

- Immediate publication on acceptance

- Inclusion in PubMed, CAS, Scopus and Google Scholar

- Research which is freely available for redistribution 